\title{
Lovely weather, isn't it? On the social dynamics of quality judgment
}

\author{
Andrzej Nowak • Katarzyna Samson • \\ Karolina Lisiecka $\cdot$ Michal Ziembowicz
}

Received: 8 September 2010/ Accepted: 27 July 2011/Published online: 9 September 2011

(C) The Author(s) 2011. This article is published with open access at Springerlink.com

\begin{abstract}
Quality is usually considered to be an attribute of an object, its degree of excellence or, more subjectively, fitness for use. Stemming from this point of view, the goal of most ranking systems is to find efficient ways of discovering, or rather uncovering, the quality of specific products or services. However, from a social psychological perspective it seems that the notion of quality belongs predominantly to the realm of social relationships. We argue that quality exists mainly between the users of an object, not within the object itself, and its functions are predominantly social, i.e. promoting interactions, creating a shared reality, or building social relationships. Quality is constructed in social interactions and used as a token therein. In the present paper we outline the social functions of quality, and discuss the implications of this perspective for designing more useful recommendation systems.
\end{abstract}

Keywords Quality · Recommendation systems · Ranking algorithms · Social dynamics

Assessment of quality has emerged as one of the leading themes in contemporary science. Ranking algorithms, dimensions of quality, efficient quality assessment and reputation systems are hot topics in current research, a fact reflected in scientific

\footnotetext{
A. Nowak $(\bowtie)$

Warsaw School of Social Sciences and Humanities, Warsaw, Poland e-mail: nowak@fau.edu

K. Samson · K. Lisiecka

Faculty of Psychology, University of Warsaw, Warsaw, Poland

M. Ziembowicz

Institute for Social Studies, University of Warsaw, Warsaw, Poland
} 
publications (e.g. Delaviz et al. 2010; Ghylin et al. 2008; Gonçalves et al. 2007; Voss 2001; Zhou et al. 2010). One of the main concerns of these projects is designing an algorithm that could provide optimal quality judgments of any object. Based upon the characteristics of a product or service that bear on its ability to satisfy stated or implied needs as well as other users' experience, such a perfect system-tailored to fit quality ranking of objects - should provide users with a ready product thus liberating them from uncertainty regarding quality standards. However attractive it may seem, such a solution appears very unsatisfactory from a social psychological point of view.

At first blush, quality evaluation may appear to be a genuine concern with defining standards and obtaining objects or services of the highest quality. However, the sheer amount of human activity related to quality assessment, and the lack of practical implications of a large proportion of it, suggests that the process of quality evaluation may itself be a goal, rather than just a means towards approximating an objectively existing quality. We propose that interactions involving quality judgments yield a source of value for individuals, independent of the judgment reached. Quality provides conversation topics, forms the basis for affiliation and gives rise to controversy. We claim that the real value of a product is indicated by what it brings to relationships between the people involved, while the actual objects of quality judgment often serve merely as a pretext for social interactions. This consideration suggests that people engage in quality judgments not only because they care about establishing quality standards but also, and more importantly, because they care about their relationships with others.

When we take a closer look at the social dynamics of quality, what we find are two processes, neither of which is directly dependent on the internal features of the object being assessed. First, quality is constructed during the interaction between people exchanging opinions about an object. Depending on the social context and the needs of the users, assessment of quality may vary and one object can be assigned numerous, often conflicting, quality judgments. Second, the common definitions of quality shared within a social group may serve as tokens of status or social roles assigned to certain objects. Those two processes are interlocked so that it is virtually impossible to grasp quality as an attribute of an object at a fixed point in time, as it is constantly subject to redefinition.

\section{Construction of quality}

A surprisingly high proportion of human activity is concentrated around quality judgment. Every other magazine on the newsstand is entirely devoted to standards of quality regarding products and services as diverse as clothing, food, IT products, or leisure activities. Almost every magazine at least features a review column. A high proportion of informal conversations is devoted to setting quality standards. "Like" and "Unlike" buttons provide important functionality on Facebook, as well as the newly introduced " +1 " button on the Google search engine. The very purpose of various websites, such as digg.com or Froogle, is to give "hits" or to grant "stars" to assorted merchandise or web content, and share opinions on their 
quality and functionality. The ubiquity of quality judgments leads us to two main conclusions. First, quality in large part is not an inherent feature of an object but it is rather being constantly defined and redefined in processes of negotiation. Second, the establishment of common quality judgments seems to be a very important social activity, to which people devote a considerable amount of time and resources.

Adjusting preferences is among the more crucial aspects of any relationship or social interaction. Scenarios of quality discussions, in the form of ready scripts, are often culturally defined. They provide subjects that are both safe and engaging. In Poland, for example, complaints about the government, public transportation, or price rises provide well-rehearsed universal scripts for successful interactions. Given that such discussions result in depressed moods, increased negative emotions, as well as decreased life satisfaction (Wojciszke 2004), the prevalence of these themes is difficult to explain in terms other than importance of shared judgments. It would seem that strengthening relations between people sharing a common fate is prioritized higher than personal happiness.

Quality discussions can be metaphorically portrayed as a "quality dance", in which partners get a chance of meeting and communicating with each other, while following a pattern of precisely defined steps. The pattern of interaction reflects interpersonal games of the kind described by Berne (1964). It provides conversational conventions-for example, the "rhythm" of weather small-talk ("lovely weather, isn't it?") — and allows for the building of bridges between people at the cognitive-emotional level based on a shared evaluation of surrounding objects. From the perspective of an individual person, the main goal for engaging in the quality dance is to build one's sense of belonging and affiliation with another person, both in terms of temporary ad hoc relationships, as well as in the sense of friendship formation. Perceived similarity of attitudes is among the strongest predictors for liking (AhYun 2002; Montoya et al. 2008).

Preferences are not properties of individuals or reflections of some objectively existing quality, but fruits of a group process. According to Festinger (1950), people experience their personal beliefs and opinions as being valid when they are shared by others similar to themselves. They constitute a shared reality for group members (Hardin and Higgins 1996). Recently, in an experimental study on preference formation in a virtual musical market, Salganik et al. (2006) showed that once the social factor comes into play, it is almost impossible to predict people's choices based on the objective quality of rated songs. Shared reality produced in group interaction influences the decisions of group members, and is influenced by them in an ongoing feedback loop process.

Shared reality defines the semantic field of a group-what topics can be discussed and what assumptions everybody accepts. Thus, the first step of the quality dance is identifying the proper representation of reality shared within a given group and changing one's behavior and presented opinions accordingly. It has been shown that people adjust their message to the preferences of their audience, which, in turn, influences their own opinion (Higgins 1981; Krauss and Fussell 1991). Sharing a representation of reality does not necessarily mean agreement, but rather by defining the important dimensions of evaluation provides a framework for discussions. Two people who do not share musical tastes (e.g. a classical music 
listener and a techno fan) would be rather uninterested in each other and likely refrain from arguing about the quality of a given piece, while two devoted jazz listeners, whose representations of reality overlap, can have a debate about the superiority of be-bop over dixieland.

The mechanism by which a shared group perception is socially constructed was demonstrated in the classic "autokinetic effect" experiment by Sherif (1936). The study participants were placed in a darkened room, where the only visual stimulus was a fixed point of light. Due to saccadic movements of the eye, the subjects perceived the point as if it were moving, and their task was to judge the direction and magnitude of the illusory movement. The reports of participants in the individual condition clustered around an average value with observable individual differences, whereas the results in the group condition converged on one common opinion or group norm. Even more strikingly, shared reality obtained by the group survived even after the originators had already left the group (Jacobs and Campbell 1961).

Sharing common criteria of quality can create social identities, which have the power of biasing intergroup relations. This phenomenon is exemplified with another classic psychological experiment, in which the authors were looking for minimal conditions sufficient to form group identity-the minimal group paradigm (Billig and Tajfel 1973; Tajfel et al. 1971). It turned out that participants developed group identities (reflected in in-group favoritism and out-group discrimination) based on absolutely random, bogus assessments of their preferences for either Klee or Kandinsky paintings. It thus seems that quality standards serve as behavioral guidelines, which the group members internalize and follow. The actual preference is not as important here as the process of establishing it, which gives rise to a group identity. Preferences never cease to evolve, and their dynamical nature corroborates their social origins.

\section{Game of status}

Once a shared definition of quality has been reached, it can be used as a token of one's social status within a given group or social context in a broader sense. Negotiating status is a prevailing motif of human interactions. As Goffman pointed out: "Co-operative activity based on differentiation and integration of statuses is a universal characteristic of social life" (1951, p. 294).

From the perspective of symbolic interactionism, sharing common meaning and experiences within a society enables consumer products or other artifacts to serve as communication symbols (Dittmar 1992). The special expressive value assigned to those objects translates to social identity and status (Goffman 1951; Levy 1959, 1999; Mason 1984; Zaltman and Wallendorf 1983). The race to achieve a higher or more desired social position, which we will further refer to as the "quality race", strongly relies on the quality of possessed objects or, as Goffman (1959) would call it, "props". It is especially visible in the phenomenon of "conspicuous consumption" (Veblen 1899), which can be defined as an act of communication that demonstrates status (Duesenberry 1967; see: Mason 1998 for a review). Possession 
of products perceived as having high quality, as well as high quality standards, may serve as a symbolic announcement aimed at important reference groups (Leigh and Gabel 1992).

Being able to skillfully recognize the accepted quality of objects is a crucial element of the winning strategy in the quality race. On the one hand, it allows for picking those objects that directly increase the holder's status. On the other, having the appropriate quality standards, commonly referred to as good taste, itself indicates status, and is often more important than material cues. This is one reason the nouveau riche do not succeed-they are extremely motivated to win the quality race and they have all the necessary means to do so, but they lack quality standards. People are also concerned with quality standards in areas outside the scope of personal interest, which can only be explained in terms of status. Someone who can barely afford a used Ford may spend hours discussing the advantage of a Maserati over a Lamborghini, while a tone-deaf person could be perorating on the sonic advantages of one set of speakers over others. Some individuals concentrate their quest for status on building expertise in a wide variety of areas that they are unlikely to be associated with directly. Just as the possession of products of high quality, being able to skillfully trash a dud or spot an up-and-coming revelation can indicate higher mastery in the quality race than can just copying the appropriate models.

High quality is usually associated with being rare, although scarcity itself does not determine an object's high quality (Goffman 1951). High quality products cannot be popular, because popular things are believed to be cheap (Mason 1981). As more individuals acquire a particular product, its perceived quality decreases. For example, in the nineteenth century, production of aluminum was so costly and difficult that it was considered a precious metal. Napoleon III is said to have given a banquet at which only the most important guests were granted the honor of using aluminum utensils, while the rest made do with gold. Hall's invention of a new lowcost method for making aluminum in the 1890 s caused its perceived quality to drop to such levels that aluminum utensils are now used predominantly in welfare agencies and prisons.

Individuals striving for the highest status want to belong to a group that establishes quality standards, and they want this group to remain an elite. By definition, an elite has to be small, or otherwise it ceases to be an elite. Only a few people are the innovators who establish quality standards and play for top positions in the quality race; the rest just copy their choices. As more and more people follow the elite-buy the trendiest clothes, read the popular books, or start going to "underground" places - the founders leave the group in an effort to set another trend. In the quality race, the evaluation of a group is dependent on its size.

The dynamics of this process resembles a minority game, where the winning solution becomes the losing one as soon as the majority discovers it (Challet and Zhang 1997). For the trendsetters, the quality game is about being in a fast-growing minority, and leaving before it approaches a majority. The followers' winning strategies are very different. The most straightforward way to win points is by joining minority groups as soon as they become influential. In this case, choosing the right trends to follow is the central concern of the players. For those who cannot compete in this manner, the game is about establishing new quality standards. If you 
can't afford a Lamborghini, argue for comfort rather than speed and buy a van. This strategy was described with respect to the compensatory role of the cultural capital. Nations that cannot compete in the field of economy champion the value of history and tradition (Zarycki 2007).

To keep the quality race going, status symbols or evaluation criteria need to be constantly changing (Goffman 1951). Followers try to catch up with the elite, so in order to keep their advantage, trendsetters keep running ahead by turning to new symbols. The quality race can only continue when there is a constant turnover of products or standards; establishing generally agreed upon quality standards stops the game. All the popular and prolonged rating activities are associated with the introduction of either new objects, new information, or new judgment criteria. The power of computers increases twofold every 2 years (Moore's law), which forces quality criteria in the IT field to be extremely dynamic. The turnover rate of songs on top lists is remarkably regular (Bentley et al. 2007). Every season new criteria of fashion emerge, not only with respect to clothing, but also food, cars and design. Promoted lifestyles also change-in the nineties everyone was a yuppie, now it's all about being a hipster. Areas as diverse as trends in child upbringing, holiday destinations, weight-losing diets, youth subcultures, college majors or spoken language are all subject to this process. In order to maintain high status, one has to remain vigilant and keep up with the changes.

The quality race is not only about acquiring the best products and services or sophisticated knowledge concerning the proper quality standards. Even more importantly, it is about communicating one's quality standards to the reference group. One may not only be a reproducer of group quality standards, but also their originator, actively involved in the process of establishing group preferences. We argue that the exchange of quality opinions is the substance of much social interaction. Quality judgments serve not only as tokens of status in social comparisons, but also as a source of categorization that underlies the group formation processes. The emergence of shared quality standards manifests itself as socially constructed fashions and trends, while the behavior of individual group members is influenced by an attained shared reality (Jochemczyk and Nowak 2006).

\section{Towards socially intelligent ranking systems}

From the above perspective social interactions concerning quality have various goals beyond pure needs-based quality assessment. In light of the mechanisms described, quality can be treated as a catalyst for social life. It seems like the mere process of negotiating quality standards is actually more important than its final result. This implies that it may be extremely difficult to find an algorithm that would approximate this process. It also places in doubt the usefulness of efforts aimed at replacing social dynamics of quality assessments with automated ranking systems.

The social quality of a product is transient and dynamic; it is being established in every interaction. Quality-centered controversies stimulate the exchanges of ideas, introduce doubts and polarize opinions, which influences the outcome of the evaluation process. What is more, the social quality of a product lies in its notability, 
i.e., the amount of buzz it evokes. The social value of objects may lie in questions to which they give rise, and how they challenge accustomed standards. For example, a deficiency of a product may nevertheless contribute to its quality, as long as it provides a topic for human interaction. Therefore, quality can be associated with ambiguity and talkability, as well as with the power to intrigue, yet these effects often have to do with novelty and are therefore short lived. Reducing ambiguity concerning the attributes of a given product may paradoxically decrease its quality.

The intention behind building automated quality ranking systems is to help people navigate in a world swarming with choices. However, if taken to the extreme, it seems likely that this idea might backfire. People engage in quality judgments not just because they care about establishing quality standards but, more importantly, because they care about their relations with others. Creating a perfect algorithm for assessing quality could act to the detriment of its social function. Understanding the social role and dynamics of quality assessment not only reveals important mechanisms in prevalent areas of human activity, but may also serve as a guideline for constructing ranking systems that would enhance, rather than destroy, social networks.

We believe that the social dynamics of quality should be translated into recommendation systems by incorporating the knowledge of how quality creates and is being created by the social tissue of interpersonal relations. Delivering a final verdict concerning the quality of objects should not be the ultimate purpose of ranking systems. On the contrary, one of their important functions should be providing a platform for social interaction. One can imagine a new generation of ranking systems that would not only predict the preferences of a potential buyer, but also involve them in quality games. Efforts should concentrate on understanding the processes in which people use quality assessment as the content of their interaction, with all of its psychological and social consequences. By doing so, ranking systems could not only enrich the social life of individuals, but also increase the value of the products. Introducing the social component into quality assessment requires an appreciation of the positive value of controversy regarding quality standards and giving credit to items that incite extreme emotions. It seems that the social quality of objects can, to some extent, be inferred from the distribution of individual quality judgments. Descriptive statistics, such as variance or extreme values of ratings, can be indicative of a product's social quality.

Some existing solutions do indeed already embed platforms that enhance human interaction concerning quality. One good example along these lines is Amazon's recommendation system- "people who bought this book also bought these ones." Amazon recognizes the importance of a reference group of similar others and promotes products that fulfilled their quality standards. Another good example is on booking.com, where posted hotel reviews are assigned to user categories, such as "mature couple", "group of friends" or "solo traveller". This endeavor is a clear attempt to activate the user's social identity, which is supposed to facilitate their choices based on the opinions of others from their in-group. Still, finding other, more advanced ways to implement the social aspect of quality assessment remains a challenge facing designers of recommendation systems. 
Acknowledgments This work was partially supported by the Future and Emerging Technologies programme FP7-COSI-ICT of the European Commission through project QLectives (grant no.: 231200).

Open Access This article is distributed under the terms of the Creative Commons Attribution Noncommercial License which permits any noncommercial use, distribution, and reproduction in any medium, provided the original author(s) and source are credited.

\section{References}

AhYun K (2002) Interpersonal communication research: advances through meta-analysis. In: Allen M, Preiss RW, Gayle BM, Burrell NA (eds) Interpersonal communication research: advances through meta-analysis. Lawrence Erlbaum Associates Publishers, Mahwah, pp 145-167

Bentley RA, Lipo C, Herzog M, Hahn MW (2007) Regular rates of popular culture change reflect random copying. Evol Hum Behav 28:151-158

Berne E (1964) Games people play. Grove Press, New York

Billig M, Tajfel H (1973) Social categorization and similarity in intergroup behaviour. Eur J Soc Psychol 3:27-52

Challet D, Zhang YC (1997) Emergence of cooperation and organization in an evolutionary game. Physica A 246:407-418

Delaviz R, Andrade N, Pouwelse JA (2010) Improving accuracy and coverage in an internet-deployed reputation mechanism. In: Proceedings of the IEEE international conference on peer-to-peer computing (P2P'2010), Delft, The Netherlands

Dittmar H (1992) The social psychology of material possessions: to have is to be. St Martin's Press, New York

Duesenberry JS (1967) Income, savings, and the theory of consumer behavior. Oxford University Press, New York

Festinger L (1950) Informal social communication. Psychol Rev 57:271-282

Ghylin KM, Abraham JK, Chen J, Drury CG, Green BD, Lawson TA, Schultz JL, Uggirala A (2008) Clarifying the dimensions of four concepts of quality. Theor Issues Ergon Sci 9:73-94

Goffman E (1951) Symbols of class status. Br J Sociol 2:294-304

Goffman E (1959) The presentation of self in everyday life. Doubleday Anchor, Garden City

Gonçalves MA, Moreira BL, Fox EA, Watson LT (2007) "What is a good digital library?"-A quality model for digital libraries. Inform Process Manag 43:1416-1437

Hardin CD, Higgins ET (1996) Shared reality: how social verification makes the subjective objective. In: Sorrentino RM, Higgins ET (eds) Handbook of motivation and cognition: the interpersonal context, vol 3. Guilford Press, New York, pp 28-84

Higgins ET (1981) Role-taking and social judgment: alternative developmental perspectives and processes. In: Flavell JH, Ross L (eds) Social cognitive development: frontiers and possible futures. pp, Cambridge University Press, pp 119-153

Jacobs RC, Campbell DT (1961) The perpetuation of an arbitrary tradition through several generations of laboratory microculture. J Abnorm Soc Psychol 62:649-658

Jochemczyk L, Nowak A (2006) Constructing a network of shared agreement: a model of communication processes in negotiations. Group Decis Negot. doi:10.1007/s10726-009-9165-y.

Krauss RM, Fussell SR (1991) Perspective-taking in communication: representations of others' knowledge in reference. Soc Cogn 9:2-24

Leigh JH, Gabel TG (1992) Symbolic interactionism: its effects on consumer behaviour and implications for marketing strategy. J Serv Market 6:5-16

Levy SJ (1959) Symbols for sale. Harv Bus Rev 37:117-124

Levy SJ (1999) Brands, consumers, symbols, and research. Sidney J. Levy on marketing. Sage Publications, Thousand Oaks

Mason RS (1981) Conspicuous consumption: a study of exceptional consumer behavior. Gower Publishing, Farnborough

Mason RS (1984) Conspicuous consumption: a literature review. Eur J Market 18:26-39 
Mason RS (1998) The economics of conspicuous consumption: theory and thought since 1700. Edward Elgar Publishing, Aldershot

Montoya R, Horton RS, Kirchner J (2008) Is actual similarity necessary for attraction? A meta-analysis of actual and perceived similarity. J Soc Pers Relat 25:889-922

Salganik MJ, Dodds PS, Watts DJ (2006) Experimental study of inequality and unpredictability in an artificial cultural market. Science 311:854-856

Sherif M (1936) The psychology of social norms. Harper \& Brothers, New York

Tajfel H, Billig MG, Bundy RF, Flament C (1971) Social categorization and intergroup behaviour. Eur J Soc Psychol 1:149-177

Veblen T (1899) The theory of the leisure class. MacMillan, New York

Voss D (2001) Better searching through science. Science 293:2024-2026

Wojciszke B (2004) The negative social world: the polish culture of complaining. Int J Sociol 34:38-59

Zaltman G, Wallendorf M (1983) Consumer behavior: basic findings and management implications. Wiley, New York

Zarycki T (2007) An interdisciplinary model of centre-periphery relations: a theoretical proposition. Reg Local Stud, Special Issue, 110-130

Zhou T, Kuscsik Z, Liu J-G, Medo M, Wakeling JR, Zhang YC (2010) Solving the apparent diversityaccuracy dilemma of recommender systems. Proc Natl Acad Sci USA 107:4511-4515 